\title{
Effects of Ischemia-like Conditions on Cultured Neurons: Protection by Low $\mathrm{Na}^{+}$, Low $\mathrm{Ca}^{2+}$ Solutions
}

\author{
William J. Goldberg, ${ }^{1}$ Richard M. Kadingo, and John N. Barrett \\ Department of Physiology and Biophysics, University of Miami School of Medicine, Miami, Florida 33101
}

\begin{abstract}
An in vitro system was used to mimic several aspects of ischemia, including low oxygen pressure, low nutrient levels, and the accumulation of cellular products thought to contribute to damage during ischemia. We replaced normal culture medium from 3-week-old basal ganglia cultures with oxygen-depleted, nutrient-deficient medium. After incubation in an almosphere of $94 \% \mathrm{~N}_{2}, 6 \% \mathrm{CO}_{2}$ for $5 \mathrm{hr}$ at $37^{\circ} \mathrm{C}$, the cultures were returned to normal medium. After a $24 \mathrm{hr}$ recovery period, cell viability was assessed in terms of cell number, electrophysiological properties, and immunohistochemical markers. When the medium used during the ischemic period was a normal balanced salt solution, more than $70 \%$ of the cells were damaged by the lowoxygen, low-glucose stress. Loss of cell processes and cell swelling were the most evident signs of damage. The majority of the cells remaining viable were astrocytes. Neuronal damage was observed only when both glucose and oxygen were deficient. Some damage was evident even at oxygen tensions of $60 \mathrm{~mm}$ $\mathrm{Hg}$ when glucose was absent from the medium; much more extensive damage was observed at tensions below $1.0 \mathrm{~mm} \mathrm{Hg}$. Lowering both extracellular sodium and calcium resulted in more than a 2 -fold increase in survival ( 70 vs $28 \%$ ). These results indicate that damage to neurons during conditions of extreme energy deprivation such as ischemia may be mediated by the influx of calcium and/or sodium.
\end{abstract}

Neuronal damage is commonly observed as a consequence of stroke or other conditions that impair circulation to the brain, but the fundamental mechanisms underlying this ischemia-induced damage remain unknown. One possible mechanism leading to neuronal damage is the intra- or extracellular accumulation of toxic substances under conditions of severe energy deprivation. Lactic acid, ammonium ions, $\mathrm{H}^{+}$ions, free fatty acids, excitatory amino acid neurotransmitters, and free radicals are some of the potentially toxic substances that accumulate during ischemia (Siesjö, 1981). Another possibility is that much of the damage might result from intracellular accumulation of $\mathrm{Na}^{+}, \mathrm{Ca}^{2+}$, or $\mathrm{Cl}^{-}$ions subsequent to energy failure. Using in vivo methods, it has been difficult to test these hypotheses and to determine whether changes in extracellular ionic concentrations or tissue metabolite levels following ischemia are epiphenomena or contribute directly to neuronal damage.

We describe a neuronal tissue culture model for studying the effects of conditions similar to those found in ischemia in vivo. We reproduced several aspects of in vivo ischemia by exposing

\footnotetext{
Received Aug. 5, 1985; revised May 22, 1986; accepted June 4, 1986.

Supported in part by NIH grants T32 NS 07044 and NS 12207 and the National Parkinson Foundation. We thank Doris Nonner for valuable technical assistance.

Correspondence should be addressed to John N. Barrett, Department of Physiology and Biophysics, University of Miami School of Medicine, P.O. Box 016430, Miami, FL 33101

1 Present address: V. A. Medical Center (151Q), 50 Irving St., Washington, DC 20422.
}

Copyright (C) 1986 Society for Neuroscience $0270-6474 / 86 / 113144-08 \$ 02.00 / 0$ dissociated cell cultures of rat basal ganglia to solutions containing no glucose and extremely low levels of oxygen $(<1$ torr $)$. The role of extracellular ion concentrations in determining cell survival was examined by varying the ionic composition of the culture medium during the ischemic period.

\section{Materials and Methods}

\section{Tissue culture}

Cultures of rat basal ganglia (striatum, globus pallidus and substantia nigra) were prepared using cells from embryos at day 15-16 of gestation. The basal ganglia were removed and placed in PBS ( $5 \mathrm{~mm} \mathrm{NaH}_{2} \mathrm{PO}_{4}$ and $155 \mathrm{~mm} \mathrm{NaCl}$ adjusted to $\mathrm{pH} \mathrm{7.2).} \mathrm{This} \mathrm{tissue} \mathrm{was} \mathrm{then} \mathrm{placed} \mathrm{in}$ defined medium supplemented with an acid-stable 55,000 Da fraction of horse serum prepared by gel filtration (Kaufman and Barrett, 1983; Kawamoto and Barrett, 1986). The tissue was dissociated into single cells by gentle trituration in a $5 \mathrm{ml}$ plastic pipette. The resulting cell suspension was plated on tissue culture dishes coated with collagen and poly(L-lysine) to a density of $1-1.5 \times 10^{3}$ cells $/ \mathrm{mm}^{2}$; Falcon $35 \mathrm{~mm}$ dishes and Nunc 24 well culture plates were used. The plated cells attached to the substrate within $30 \mathrm{~min}$ and survived for more than 6 months in these cultures. The culture medium was replenished every 2 weeks by replacing $75 \%$ of the medium with fresh medium. Over $90 \%$ of the cells in these cultures were neuronal, as indicated by the presence of action potentials and binding of tetanus toxin. Nearly all the remaining cells were astrocytes, as indicated by the binding of antibodies against glial fibrillary acidic protein (GFAP). Antibiotic or antimitotic agents were not used in the culture medium.

\section{Induction of ischemia-like conditions}

Three-week-old basal ganglia cultures were placed under ischemia-like conditions in a 2-step procedurc. First the normal medium was replaced with a nutrient-deficient, balanced salt solution (see below). Cultures were washed 3 times to ensure adequate removal of glucose. The culture dishes were then transferred to a nitrogen/carbon dioxide atmosphere glove box. The salt solution was then replaced with an oxygen-depleted solution of the same chemical composition; oxygen depletion was ensured by bubbling the solution with $94 \%$ nitrogen $/ 6 \%$ carbon dioxide for $30 \mathrm{~min}$. The cultures were then sealed in a metal chamber that was continuously purged with a mixture of $94 \% \mathrm{~N}_{2} / 6 \% \mathrm{CO}_{2}$ for $5 \mathrm{hr}$. The chamber was kept in a $37^{\circ} \mathrm{C}$ incubator during the $5 \mathrm{hr}$ period of ischemia. At the end of this period the "ischemic" medium was replaced with oxygenated culture medium. Cell survival was assessed (see below) after $24 \mathrm{hr}$ of recovery in normal medium.

\section{Nutrient-deficient solutions}

Osmotically balanced, nutrient-deficient, balanced salt solutions were prepared as follows: $20 \mathrm{mM} \mathrm{NaHCO}_{3}, 5 \mathrm{mM} \mathrm{KHCO}_{3}, 1.5 \mathrm{mM} \mathrm{MgCl}_{2}$, $5 \mathrm{~mm}$ lactic acid, $21 \mu \mathrm{M} \mathrm{EGTA}, 20 \mu \mathrm{M} \mathrm{CaCl}_{2}$, and amino acids and vitamins at $1 / 10$ the concentrations used in our culture medium. Highsodium solutions contained $120 \mathrm{~mm} \mathrm{NaCl}$, whereas low-sodium solutions contained $25 \mathrm{~mm} \mathrm{NaCl}$ and $70 \mathrm{~mm} \mathrm{KCl}$. Calcium was added as $\mathrm{CaCl}_{2}$ to a concentration of $0-2 \mathrm{mM}$. Sorbitol was added to all solutions to bring the osmotic pressure to $300-310$ mOsm. A second series of low-sodium solutions was also prepared in which choline chloride, rather than potassium chloride, was used to replace sodium. These solutions 
differed from the first series in that they contained $112 \mathrm{~mm}$ choline, 5 $\mathrm{mM} \mathrm{K}{ }^{+}$, and $135 \mathrm{mM} \mathrm{Cl}^{-}$.

\section{Removal of oxygen from culture medium}

Two procedures were tested for rapid removal of oxygen from culture medium. The first involved placing the culture dish containing medium in a sealed chamber and purging the chamber with a mixture of $94 \%$ $\mathrm{N}_{2} / 6 \% \mathrm{CO}_{2}$ for $5 \mathrm{hr}$ at a rate of $21.6 \mathrm{ml} / \mathrm{min}(18 \mathrm{ml}$ gas phase chamber volume, $0.5 \mathrm{ml}$ liquid volume of medium). Changes in the partial pressure of oxygen in the medium were continuously monitored using a platinum microelectrode. The tip of the electrode was immersed in the culture medium and the body of the clectrode anchored to the inner surface of the chamber cover. The current generated by the electrode was measured with an amplifier system and converted to oxygen tension using a calibration curve for the electrode.

In the second procedure, oxygen was depleted from the nutrientdeficient salt solution before the solution was placed on the cells. This was accomplished by bubbling a purified nitrogen/carbon dioxide mixture $\left(94 \% \mathrm{~N}_{2} / 6 \% \mathrm{CO}_{2}\right)$ directly into the solution for $30 \mathrm{~min}$ and then replacing the normal culture medium with the oxygen-depleted salt solution. Contamination by oxygen from the air was eliminated by performing this exchange in a glove box purged with the nitrogen/carbon dioxide gas mixture. This second procedure for the removal of oxygen was routinely used. The relationship between dissolved oxygen tension and cell survival was examined by preequilibrating the test solution with a series of mixtures of carbon dioxide ( $6 \%$ for all), nitrogen, and oxygen and then purging the chamber with a continuous stream of gas of the same composition for $5 \mathrm{hr}$.

\section{Assessment of cell survival by morphological criteria}

Prior to the induction of ischemia, representative fields were marked with a scribe on the bottom surface of the culture dish. The ratio of healthy cells to the total number of recognizable cell bodies was calculated for each field. Cells were counted as healthy if they appeared as a phase-dark cell body with a surrounding halo and displayed no sign of either inclusion bodies or membrane blebbing. Both neurons and glial cells were included in these cell counts. More than $99 \%$ of the cells met these criteria before the beginning of the stress period. Cell counts were repeated after $5 \mathrm{hr}$ of ischemia, and again after $24 \mathrm{hr}$ of recovery. Cells that were swollen (clarified cytoplasm with an eccentric nucleus) or had obvious signs of vacuolization, inclusion bodies, or membrane blebbing were counted as nonviable. Swelling was quantitated by comparing the cell body diameter of identified cells in photographs taken before and after the ischemic period. The significance of differences in cell survival under a variety of ionic conditions was determined using a 1-way analysis of variance followed by Duncan's multiple range test.

\section{Assessment of cell viability using vital dyes}

One of 3 dyes (Trypan blue, Erythrosin B, or fluorescein diacetate) was added to the culture after $24 \mathrm{hr}$ of recovery following the $5 \mathrm{hr}$ ischemic period. Two drops of dye stock solution (see below) were added to the existing medium $(0.5 \mathrm{ml})$ in the culture dish. After 5 min the cultures were examined under phase-contrast optics, and the number of cells was counted in previously marked fields. Cells that appeared as dark blue (Trypan blue) or red (Erythrosin B) on a lighter background were counted as nonviable. Fluorescein diacetate-treated cultures were examined with fluorescence optics. The dye was excited by a $100 \mathrm{~W}$ tungsten/halogen lamp through an epi-illuminating fluorescence system (Nikon Diaphot). Cells that appeared as green fluorescent spots were counted as viable.

\section{Trypan blue and Erythrosin B stock solutions}

Stock solutions $(0.4 \%)$ were made according to the procedure of Phillips (1973). Trypan blue or Erythrosin B (0.4 g) was added to $95 \mathrm{ml}$ distilled water containing $0.81 \mathrm{~g} \mathrm{NaCl}, 0.06 \mathrm{~g} \mathrm{KH}_{2} \mathrm{PO}_{4}$ and $0.05 \mathrm{~g}$ methyl-phydroxybenzoate. The solution was heated to boiling to dissolve all materials, cooled, and adjusted to $\mathrm{pH} 7.2$ with $1 \mathrm{~N} \mathrm{NaOH}$. The final volume was then adjusted to $100 \mathrm{ml}$ with distilled water. The dye solutions were sterile-filtered and stored at room temperature.

\section{Fluorescein diacetate stock solution}

Fluorescein diacetate was dissolved in dimethyl sulfoxide at a concentration of $10 \mathrm{mg} / \mathrm{ml}$ and then diluted 100 -fold in culture medium. The

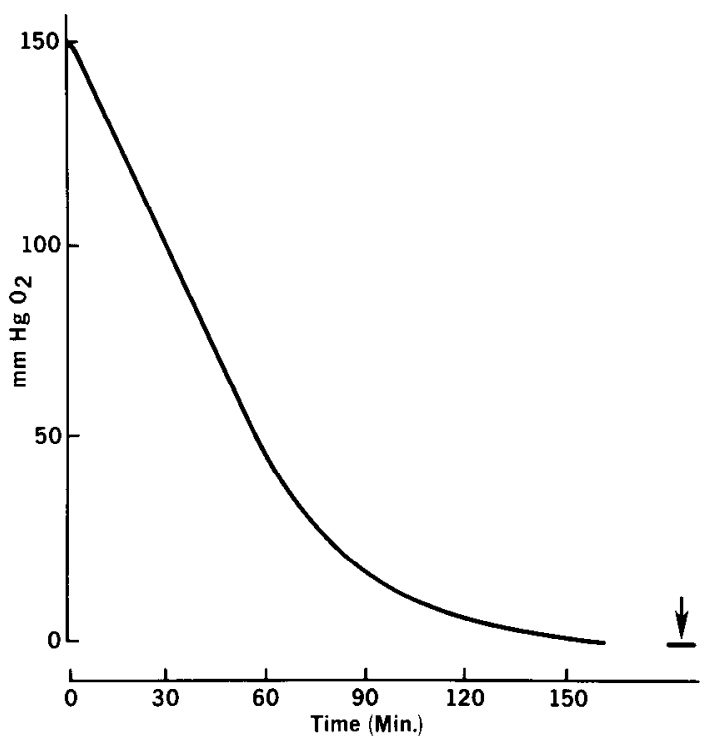

Figure 1. Oxygen tension equilibration as a function of time. The ordinate gives the oxygen tension in a saline solution within the experimental chamber used to produce ischemia-like conditions. The solution was preequilibrated with air and at time zero the chamber was continuously purged with nitrogen gas $\left(99.999 \% \mathrm{~N}_{2}\right)$. Oxygen tension in the solution was monitored continuously by a platinum electrode. Note the long time required to reduce the oxygen tension from $150 \mathrm{~mm}$ to below $1 \mathrm{~mm} \mathrm{Hg}$.

diluted solution was filtered to remove precipitates and stored at $4{ }^{\circ} \mathrm{C}$, protected from light.

\section{Immunohistochemistry}

Binding of rabbit anti-human GFAP antibodies by cultured cells was assessed after $5 \mathrm{hr}$ of ischemia and $24 \mathrm{hr}$ of recovery. The cells were fixed in 10\% buffered formalin for $5 \mathrm{~min}$ and permeabilized for $1 \mathrm{~min}$ with $95 \%$ ethanol at $-20^{\circ} \mathrm{C}$. The cells were then rinsed with culture medium. The medium was removed and replaced with $100 \mu \mathrm{l}$ of rabbit anti-human GFAP serum (supplied by Dr. Lawrence Eng, Palo Alto, CA) diluted $1: 100$. After a $20 \mathrm{~min}$ incubation at $37^{\circ} \mathrm{C}$ the primary antibody was removed and the cells rinsed with culture medium. The medium was removed and $100 \mu$ of fluorescein-isothiocyanate-coupled goat anti-rabbit IgG (Cappel Laboratories, Inc.) diluted 1:50 was added. After incubation at $37^{\circ} \mathrm{C}$ for $30 \mathrm{~min}$, the antiserum was removed, and the cells were rinsed with PBS. The cells were then mounted in 50\% glycerol in PBS and observed with an epifluorescent Nikon Diaphot equipped with the appropriate filters.

\section{Results}

Measurements of the oxygen tension in the medium indicated that when oxygen was removed by diffusion alone the oxygen level fell with a half-time of about $45 \mathrm{~min}$ and required 160 min to fall below 1 torr (Fig. 1). When the medium replacement procedure (see Materials and Methods) was used, oxygen tension measurements in the resulting solution were not significantly different from those made in a commercial "zero oxygen" standard solution, indicating that initial oxygen tensions were below 1 torr.

Some dehydration of the culture medium occurred in the sealed chamber during a $5 \mathrm{hr}$ test period; measurements of the osmolarity of the medium before and after the experiment were $330 \pm 1.7$ and $350 \pm 2.4 \mathrm{mOsm}$, respectively $(p<0.001)$. The effects of such an increase in osmolarity on cell viability appear to be negligible; cultures remaining in 350 mOsm medium for $5 \mathrm{hr}$ and then returned to normal medium exhibited no sign of damage or swelling.

After a $5 \mathrm{hr}$ stress period in "normal" salt solution (140 mM 

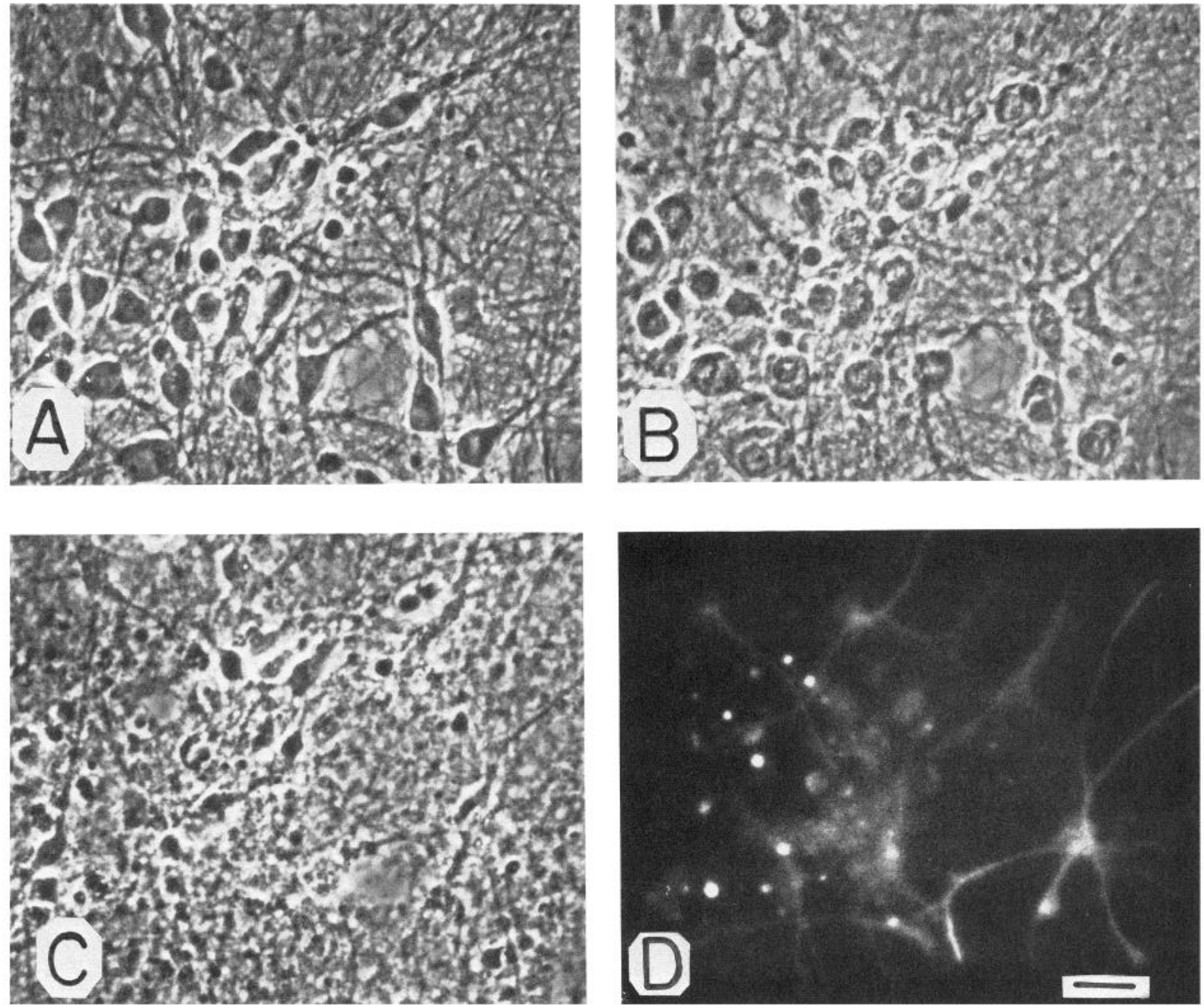

Figure 2. Effects of ischemia on cultured basal ganglia under normal ionic conditions $\left(140 \mathrm{~mm} \mathrm{Na}^{+}, 5 \mathrm{mM} \mathrm{K}^{+}, 2 \mathrm{mM} \mathrm{Ca}^{2+}, 1.5 \mathrm{~mm} \mathrm{Mg} \mathrm{Mg}^{2+}\right)$. Representative fields were photographed under phase-contrast optics. $A$, Prior to the induction of ischemia, neurons were observed as phase-dark cell bodies with surrounding halos. A dense network of cell processes can be seen. Glial cells appear as flat, phase-dark cells. $B$, After 5 hr of ischemia and return to normal culture medium there was a significant loss of cell processes. The cytoplasm has lost its granular appearance and becomes more transparent. Eccentric nuclei are common. $C$, At $24 \mathrm{hr}$ postischemia, only glial processes can be clearly distinguished. Most neuronal cell bodies have either disintegrated or remain in a swollen state. Glial cell bodies are more readily apparent than in $A$ and $B$. $D$, Anti-GFAP labeling $24 \mathrm{hr}$ postischemia demonstrates a high degree of glial process integrity. Calibration bar, $20 \mu \mathrm{m}$.

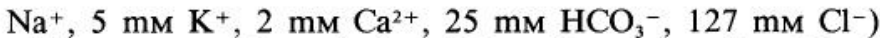
without oxygen, the majority of the cells were swollen. Those cells not already swollen at the end of the ischemic period usually underwent a "swelling reaction" in which they swelled to 180 $185 \%$ of their original diameter within 30 min after the return to normal medium. The cytoplasm became more transparent and lost its fine granular appearance, while the nucleus and nucleolus became very prominent. Brownian movement of particles within the cytoplasm and nucleus was frequently observed, and the nucleus was often eccentric. Before the induction of ischemia, neuronal and glial processes had a smooth appearance and formed an extensive network along the surface of the substrate. This network was partially broken up immediately after the ischemic period, and the damage progressed over the next $24 \mathrm{hr}$, resulting in almost total destruction of cell processes (Fig. 2).

Approximately $85 \%$ of the cells were superficially intact at the end of the $5 \mathrm{hr}$ ischemic period, but only $27.9 \pm 4.5 \%$ of the cells remained viable $24 \mathrm{hr}$ after the end of the ischemic test period. At this time, cells remaining in the swollen state and those exhibiting extensive vacuolization were counted as nonviable; more than $90 \%$ of such cells burst open and/or disappeared completely within the next $72 \mathrm{hr}$. Immunohistochemical staining of control cultures for GFAP revealed that $5-15 \%$ of the original cell population were glia; the majority of these cells had morphologies similar to those of astrocytes in vivo. In contrast, $30-50 \%$ of the postischemic cell population was glial after $24 \mathrm{hr}$ of recovery. In control cultures, glial cells were often covered by overlying processes and neuronal cell bodies. As neuronal cell bodies and processes disintegrated following ischemia, the underlying cells were exposed, making them more apparent under phase-contrast optics (Fig. 2). However, overlying cells did not interfere with identification of astrocytes by the fluorescein-labeled anti-GFAP marker.

Neurons cultured from different brain regions displayed similar sensitivities to the ischemic stress. Three-week-old cultured neurons from the cerebral cortex $(35.1 \pm 2.4 \%$ survival, $n=3)$ and spinal cord $(0.8 \pm 0.8 \%$ survival, $n=4)$ were damaged by exposure to ischemia-like conditions for $5 \mathrm{hr}$.

In some experiments, cell viability was assessed both by morphological criteria and by Trypan blue or Erythrosin B exclusion. Cells scored as viable by morphological criteria under phase- 
contrast optics were nearly always (99\%) judged to be viable by the dye-exclusion procedures. However, swollen and extensively vacuolated cells often failed to take up Trypan blue and Erythrosin B, thus passing the dye test for viability. Even cells so swollen that Brownian movement of particles was apparent within the cytoplasm and nucleus often excluded the vital dyes. Accumulation and cleavage of fluorescein diacetate, a commonly accepted marker for cell viability (Rotman and Papermaster, 1966), also gave anomalous results; swollen and vacuolated cells often demonstrated intense fluorescence. Initial damage to the cells appeared to occur intracellularly, followed by loss of membrane integrity. At the end of the $24 \mathrm{hr}$ recovery period, some cells had swollen to as much as $240 \%$ of their original diameter and had lost much of their internal structure. These cells were still defined by a limiting outer membrane and continued to exclude Trypan blue and Erythrosin B. Thus, Trypan blue and Erythrosin B were excluded by some cells that were clearly nonviable. The best predictor of viability was the appearance of cells under phase-contrast optics $24 \mathrm{hr}$ after the period of ischemia. Neurons with no apparent swelling at this time continued to survive and were capable of maintaining a resting potential of at least $-40 \mathrm{mV}$; swollen cells gave resting potential measurements between 0 and $-6 \mathrm{mV}$.

The severity of damage to 3 -week-old cultures varied with the oxygen concentration in the atmosphere contained in the sealed chamber during the $5 \mathrm{hr}$ period of ischemia. An oxygen tension of 60 torr supported survival of $76 \%$ of the cell population, whereas tensions between 1 and 10 torr resulted in 56$65 \%$ survival; at oxygen tensions below 1 torr, a further reduction to $20-27 \%$ survival was observed (Fig. 3).

The neuronal cultures were insensitive to the presence of elevated lactate concentrations in the medium. Exposure to culture medium containing $20 \mathrm{~mm}$ lactate (adjusted to $\mathrm{pH} 7.2$ ) for $24 \mathrm{hr}$ did not produce detectable cell damage. Exposure to medium containing $50 \mathrm{~mm}$ lactate (adjusted to $\mathrm{pH} \mathrm{7.2)} \mathrm{for} 24 \mathrm{hr}$ resulted in a variable (50-100\%) survival $24 \mathrm{hr}$ later. The presence or absence of $5 \mathrm{~mm}$ lactate in the test salt solutions did not produce any observable difference in cell survival. Unless otherwise specified, the experimental test solutions contained 5 mm lactic acid (see Materials and Methods) in order to provide an energy substrate in the presence of oxygen.

Since some ischemic damage might be due to internal accumulation of $\mathrm{Na}^{+}$and/or $\mathrm{Ca}^{2+}$, we examined the effect of changing external ion concentrations on neuronal damage. When the extracellular concentrations of sodium, potassium, and calcium present throughout the $5 \mathrm{hr}$ period of ischemia were altered ( 45 $\mathrm{mM} \mathrm{Na}{ }^{+}, 75 \mathrm{mM} \mathrm{K}^{+}$, and $1 \mu \mathrm{M} \mathrm{Ca}^{2+}$ ) to more closely resemble their intracellular concentrations, a substantial improvement in cell survival was observed: $69.0 \pm 4.2 \%$ survival (mean $\pm \mathrm{SEM}$ ) versus the $27.9 \pm 4.5 \%$ survival in the normal $\mathrm{Na}^{+}$, normal $\mathrm{Ca}^{2+}$ solution. In some experiments, both cell bodies and processes were preserved, while in others, damage to processes was observed. When the extracellular calcium concentration was maintained at $2 \mathrm{~mm}$ in the presence of $45 \mathrm{~mm} \mathrm{Na}^{+}$and $75 \mathrm{~mm}$ $\mathrm{K}^{+}$, there was significantly less protection than in the equivalent low-calcium solution $(p<0.05)$. The use of solutions with intermediate calcium concentrations $(10$ and $100 \mu \mathrm{M})$ resulted in intermediate $(p<0.05)$ survival rates of $43.3 \pm 8.4 \%$ and $47.7 \pm 6.7 \%$, respectively (Figs. 5 and $6 \mathrm{~A}$ ). If the extracellular calcium concentration was decreased while normal sodium and potassium levels were maintained $\left(140 \mathrm{~mm} \mathrm{Na}^{+}, 5 \mathrm{~mm} \mathrm{~K}{ }^{+}\right.$, and 1,10 , or $100 \mu \mathrm{M} \mathrm{Ca}{ }^{2+}$ ) a slight, but not statistically significant, protection from ischemic damage was observed: $44.3 \pm 9.2$, $39.2 \pm 6.9$, and $48.0 \pm 6.5 \%$ survival, respectively, versus $27.9 \pm 4.5 \%$ survival in the equivalent $2 \mathrm{~mm} \mathrm{Ca}^{2+}$ solution (Figs. 4, 6B).

When choline chloride was substituted for the increased potassium in the low-sodium, low-calcium solution $\left(45 \mathrm{~mm} \mathrm{Na}{ }^{+}\right.$,

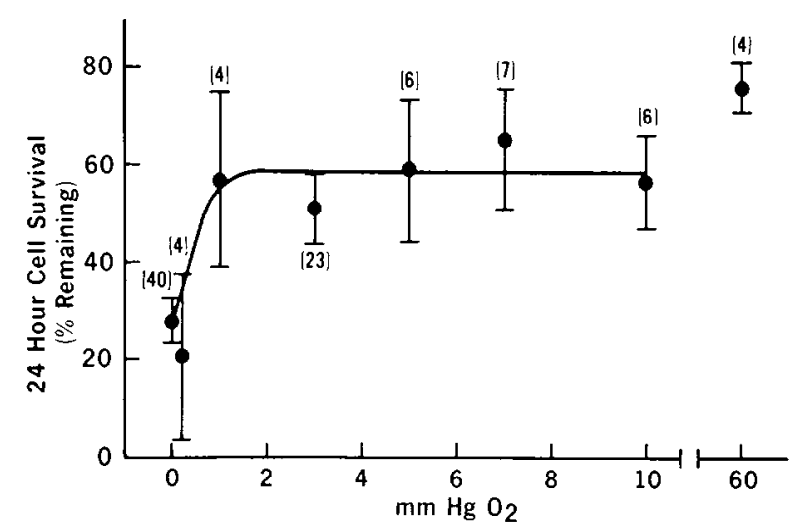

Figure 3. Relationship between oxygen tension and cell survival. The percentage of cells surviving $24 \mathrm{hr}$ after a $5 \mathrm{hr}$ ischemic insult is plotted against dissolved oxygen tension. Each point represents the mean \pm SEM for the number of observations in brackets.

$5 \mathrm{mM} \mathrm{K}^{+}, 112 \mathrm{~mm}$ choline, $135 \mathrm{mM} \mathrm{Cl}^{-}, 1 \mu \mathrm{M} \mathrm{Ca}^{2+}$ ), a similar protective effect was observed following a $4 \mathrm{hr}$ period of oxygen and glucose deprivation: $97.4 \pm 7.1 \%$ survival $(n=4)$ versus $85.2 \pm 5.1 \%$ survival $(n=3)$ in the equivalent high-potassium (75 mm) solution.

After some experiments we recorded intracellularly from the cells exposed to ischemia-like conditions in solutions of varying $\mathrm{Na}^{+}$and $\mathrm{Ca}^{2+}$ concentrations. Within $5 \mathrm{hr}$ after the $5 \mathrm{hr}$ ischemic period, many of the cells in the cultures treated with the low$\mathrm{Ca}^{2+} /$ low $-\mathrm{Na}^{+}$solution during the stress period gave resting potentials of -30 to $-40 \mathrm{mV}$ and produced small action potentials of $20-35 \mathrm{mV}$ amplitude $(n=90)$ either in response to the initial electrode penetration or to intracellular current pulses. After $24 \mathrm{hr}$ of recovery from the ischemic insult, more than $90 \%$ of the neurons remaining intact had resting potentials in the range of -40 to $-60 \mathrm{mV}$ and gave action potentials of 20 $60 \mathrm{mV}(n=90)$. Spontaneous synaptic activity was not observed at these times but was present after 2 weeks of recovery.

In contrast to the results from the low-sodium/low-calcium experiments, fewer than $1 \%$ of the cells exposed to the normal sodium (140 mm)/normal calcium (2 mM) solution during the ischemic period could be stimulated to give action potentials at either 4 or $24 \mathrm{hr}$ postischemia. Cells from these experiments that remained intact at $24 \mathrm{hr}$ had resting potentials between -20 and $-50 \mathrm{mV}$ but did not give action potentials in response to the electrode penetration, or to intracellular injection of hyperpolarizing (anode break excitation) or depolarizing current pulses.

Two methods for decreasing synaptic activity were tested for efficacy in preventing ischemic damage. When the extracellular magnesium concentration was raised to $10 \mathrm{~mm}$, no protection from damage was observed. Also, no protection was observed when $8 \mathrm{~mm}$ D-glutamyl-glycine (DGG), a blocker of glutamate receptors, was added to the bathing solution. However, when addition of DGG was combined with lowering the extracellular calcium concentration to $1 \mu \mathrm{M}$, an increase in cell survival was noted during the early phases of the recovery period (1-4 hr); both the swelling of cell bodies and loss of cell processes were absent. However, most of the cells initially protected by DGG disintegrated during the remainder of the $24 \mathrm{hr}$ recovery period. At $24 \mathrm{hr}$ postischemia, damage and survival were similar with and without DGG.

Transfer of medium from cultures severely damaged by ischemia to control cultures did not result in significant cell loss (100\% survival) over a $2 \mathrm{~d}$ exposure period. Thus, at least in this culture system, there was no sign of toxicity from agents released into the medium by cells during the ischemic period. 

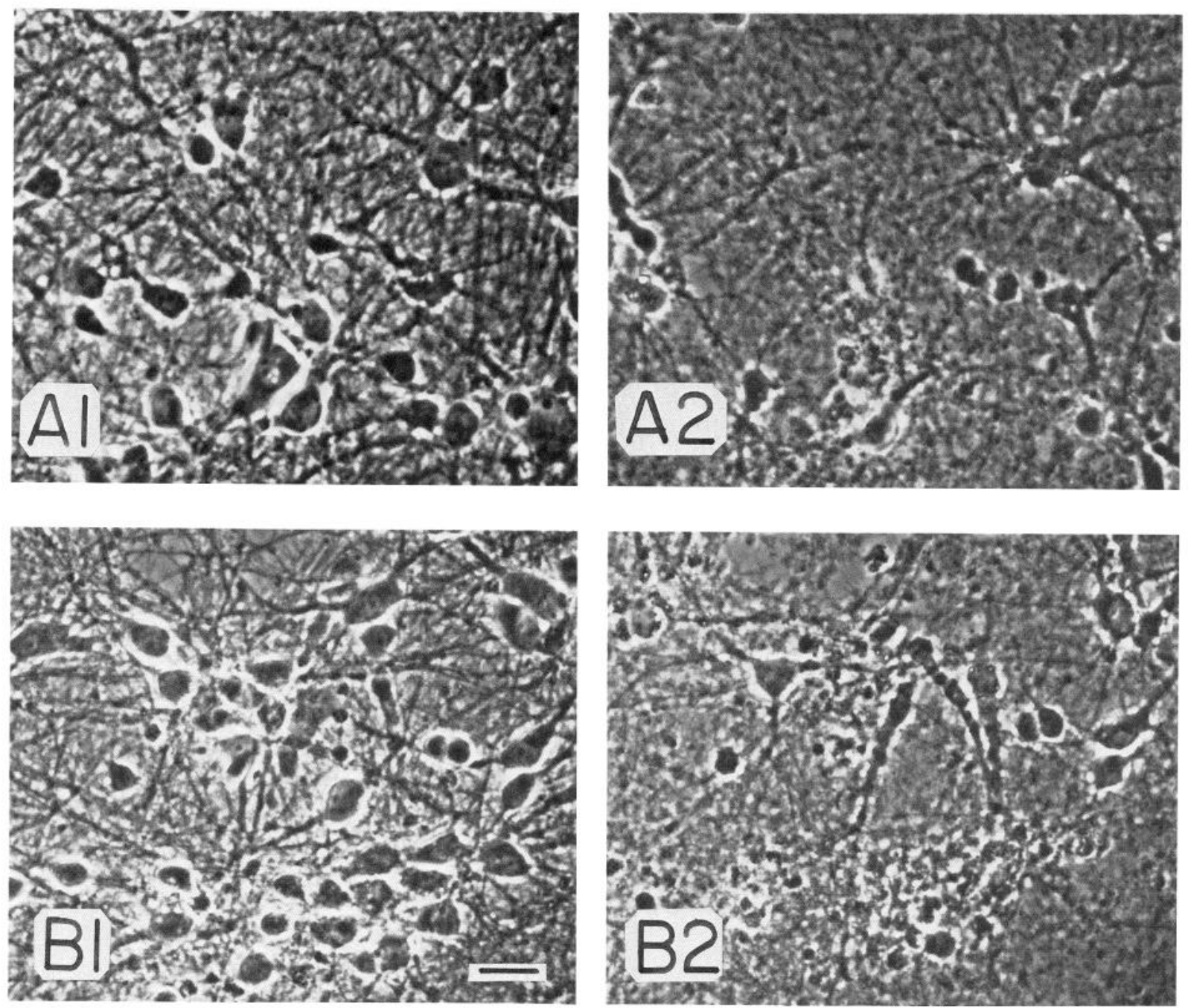

Figure 4. Effects of extracellular calcium concentration on cell survival in high-sodium medium. Representative fields were photographed under phase-contrast optics prior to the onset of a $5 \mathrm{hr}$ period of ischemia and again after a $24 \mathrm{hr}$ recovery period. $A 1$, Neurons in medium containing $2 \mathrm{mM} \mathrm{Ca}^{2+}$ prior to the induction of ischemia appear as phase-bright cell bodies, and there is an extensive network of neuronal and glial processes. $A 2$. After the $24 \mathrm{hr}$ recovery period, the majority of neuronal cell bodies and processes have disintegrated, revealing underlying glial cells. Some remaining cells contain small inclusion bodies. Glial cell processes are relatively intact. $B 1$, Preischemic basal ganglia neurons in medium containing $1 \mu \mathrm{M} \mathrm{Ca}^{2+}$ are similar in appearance to those in $A 1$. B2, At $24 \mathrm{hr}$ postischemia, the majority of cells are severely damaged, and almost all neuronal processes have disintegrated. The remaining cells are predominantly astrocytes. Calibration bar, $20 \mu \mathrm{m}$.

\section{Discussion}

In our culture system, cells survived for more than $16 \mathrm{hr}$ on either glycolysis alone (glucose but no oxygen) or aerobic metabolism without glucose (lactic acid and oxygen). However, removal of both oxygen and glucose for $5 \mathrm{hr}$ resulted in cell damage and death in 3-week-old, neuron-rich basal ganglia cultures. The first signs of damage visible with the light microscope were swelling of cell bodies and loss of processes. During the next $24 \mathrm{hr}$ the majority of cells continued to swell and disintegrate. Internal structure was lost, but membrane integrity was often preserved until the time of disintegration.

This time course is somewhat slower than that described by Ames and Nesbett $(1983 a-c)$ for isolated retina subjected to a similar insult, but it is more rapid than the time course described by Rothman $(1983,1984)$ for cultured hippocampal cells deprived of oxygen but not glucose. The more rapid onset of irreversible damage observed by Ames is most likely due to the differences between neurons and astrocytes in monolayer culture and intact tissues such as the isolated retina. The higher cell density and greater synaptic connectivity of the retina preparation may result in a more rapid rate of energy consumption and depletion of extracellular nutrients compared to neuronal cell cultures. Consequently, the time required for energy demand to exceed energy supply is decreased. In addition, the retina experiments were performed with a very low ratio of extracellular fluid to tissue volume, such that toxic compounds released or produced during ischemia could have accumulated. Ames reported that the bathing medium from an ischemic retina was toxic to nonischemic control retinas. No toxic activity of ischemia-conditioned medium was found in the present study, but our tissue culture system used a relatively large ratio of extracellular fluid to cell volume, and toxic factors may have been diluted to the point of ineffectiveness.

The longer time course reported by Rothman $(1983,1984)$ for anoxia-induced cell death may be related to 2 factors. Our direct replacement of the culture medium with oxygen-depleted medium yields a more rapid onset of oxygen deprivation. We found that culture medium containing dissolved oxygen requires more than $2 \mathrm{hr}$ to equilibrate with an oxygen-free atmosphere 

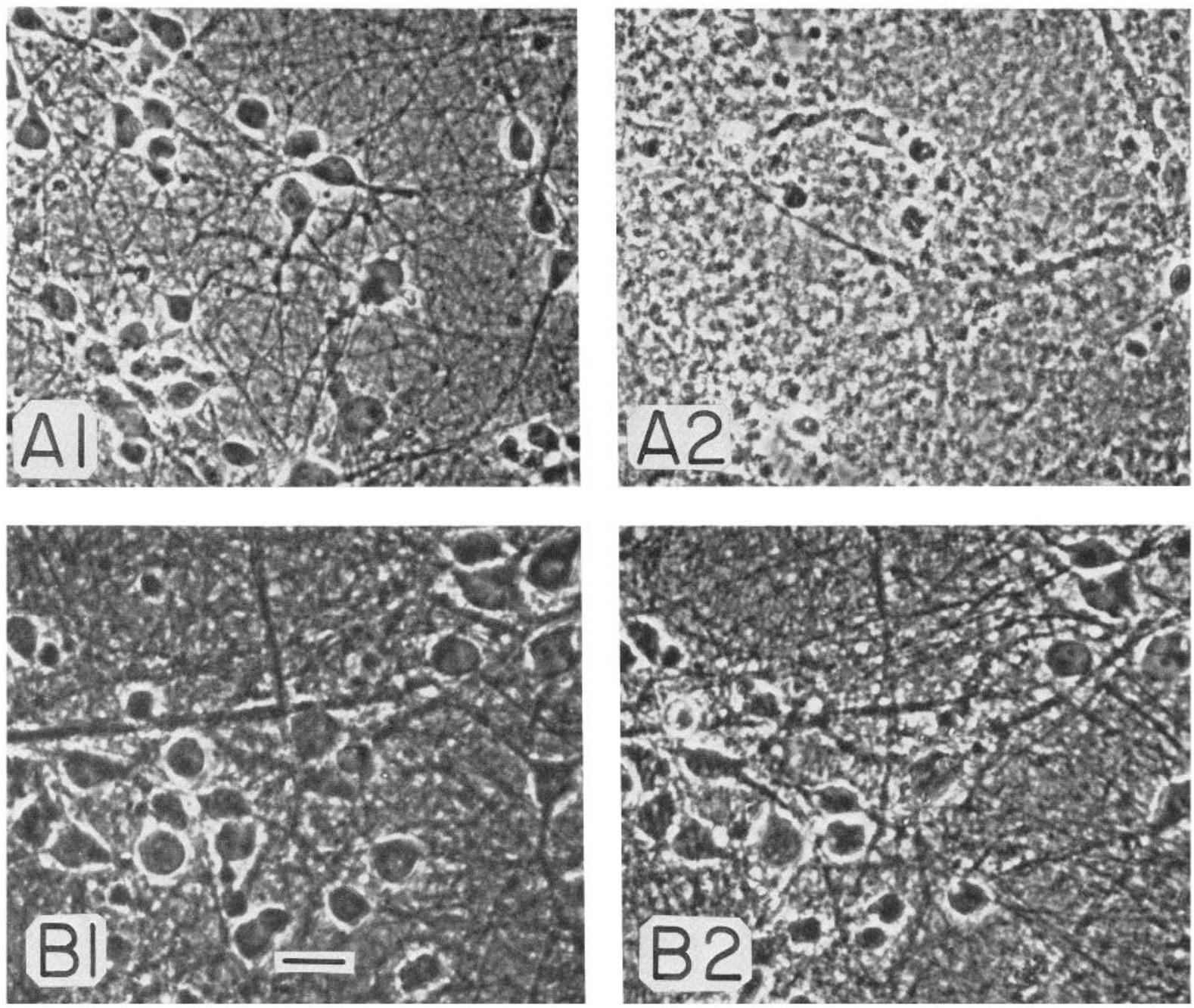

Figure 5. Effects of extracellular calcium concentration on cell survival in low-sodium medium. Representative fields were photographed under phase-contrast optics prior to the onset of a $5 \mathrm{hr}$ period of ischemia and again after a $24 \mathrm{hr}$ recovery period. Al, Neurons in medium containing $2 \mathrm{~mm} \mathrm{Ca}^{2+}$ prior to the onset of ischemia appear as phase-bright cell bodies, and an extensive network of neuronal and glial processes is present. $A 2$, At $24 \mathrm{hr}$ postischemia, the majority of neuronal cell bodies and processes have disintegrated, revealing underlying glial cells. Glial cell processes are relatively intact. $B 1$, Basal ganglia neurons in $1 \mu \mathrm{M} \mathrm{Ca}{ }^{2+}$ solution prior to ischemia are similar in appearance to those in $A 1$. B2, At $24 \mathrm{hr}$ after a $5 \mathrm{hr}$ period of ischemia, the cells in this field are relatively well preserved. Note the large number of surviving cell bodies and relative integrity of the network of cell processes. The photomicrograph in $B 2$ appears lighter and clearer than that in $B 1$ due to a loss of cell bodies and cell processes. Calibration bar, $20 \mu \mathrm{m}$.

in order to achieve dissolved oxygen tensions below 1 torr. Second, anoxic cells may be able to survive on glycolysis alone in culture. In our culture system, cells were able to withstand up to $16 \mathrm{hr}$ of anoxia without obvious signs of cell damage.

In addition to energy depletion, substantial alterations in extracellular ion composition have been consistently observed following ischemia in vivo. As energy is depleted, the ionic concentration gradients are dissipated, resulting in a net movement of sodium and calcium into the cells and potassium out of the cells. Since the extracellular space is small compared to the cell volume, these shifts are reflected in decreased extracellular sodium and calcium concentrations and elevated potassium levels. In a tissue culture system, however, the ratio of extracellular fluid to cellular volume is very large, and ion fluxes across the cell membrane have little or no effect on extracellular ion concentrations. However, significant alterations in intracellular ion concentrations would still occur.

Ion fluxes in a culture system can be manipulated by altering extracellular ion concentrations. Under conditions of energy depletion, changing the extracellular concentrations of $\mathrm{Na}^{+}$and
$\mathrm{K}^{+}$to more closely match their intracellular concentrations should reduce the net intracellular loss of $\mathrm{K}^{+}$and accumulation of $\mathrm{Na}^{+}$and $\mathrm{Ca}^{2+}$. To test whether changes in intracellular ionic concentrations are an important factor in producing the damage during ischemia, we minimized these changes by producing ischemia-like conditions in cultures with a medium resembling intracellular fluid $\left(45 \mathrm{~mm} \mathrm{Na}{ }^{+}, 75 \mathrm{~mm} \mathrm{~K}{ }^{+}\right.$, and $\left.1 \mu \mathrm{M} \mathrm{Ca}^{2+}\right)$. Approximately $70 \%$ of the cells survived a $5 \mathrm{hr}$ period of oxygen and glucose deprivation under such ionic conditions; only about $30 \%$ of the cells survived this insult in medium having a normal ionic composition. While survival of cell bodies was a consistent finding in the low sodium, low calcium solution, the network of processes was protected to a variable extent. There was always some loss of processes, as shown in Figure $5 B$.

Intracellular accumulation of calcium ions has been proposed as a cause of damage during ischemia in the brain (Siesjö, 1981), as well as in a number of other systems (Schanne, 1979). When calcium was buffered to a low level $(1 \mu \mathrm{M})$, however, no increase in neuronal survival was observed as long as sodium and potassium were held at normal concentrations (140 and $5 \mathrm{~mm}$, 

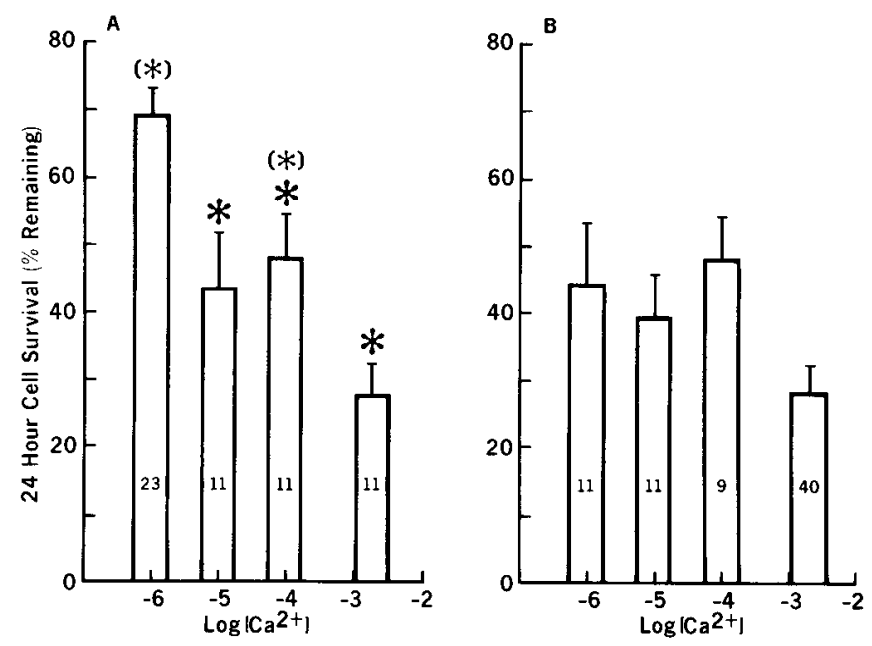

Figure 6. Effect of $\mathrm{Ca}^{2+}$ concentration on cell survival following ischemic stress. $A$, Histogram plotting the percentage of cells surviving 24 $\mathrm{hr}$ after a $5 \mathrm{hr}$ period of ischemia $\left(\mathrm{O}_{2}<1 \mathrm{~mm} \mathrm{Hg}\right.$ and $0 \mathrm{~mm}$ glucose $)$ versus the $\mathrm{Ca}^{2+}$ concentration in a low- $\mathrm{Na}^{+}$, high- $\mathrm{K}^{+}$medium (see Materials and Methods). $B$, Histogram plotting cell survival versus $\mathrm{Ca}^{2+}$ concentration in high- $\mathrm{Na}^{+}$, low- $\mathrm{K}^{+}$medium (see Materials and Methods). Histogram bars represent the mean \pm SEM for the number of cultures indicated within the bar. Significance levels were determined using a 1-way analysis of variance followed by Duncan's multiple range test. *, significantly different from the $10^{-6} \mathrm{M} \mathrm{Ca}^{2+}$ group at $p<0.05$; $\left(^{*}\right)$, significantly different from the $2 \times 10^{-3} \mathrm{M} \mathrm{Ca}^{2+}$ group at $p<0.05$.

respectively). Under low-sodium, high-potassium conditions, neuronal viability following an ischemic insult varied inversely with the extracellular calcium concentration. A significant sparing of neurons was observed when the decrease in calcium was combined with lowered sodium ( $45 \mathrm{~mm}$ ) and elevated potassium (75 mm) levels. No statistically significant sparing of neurons was observed in a solution containing $45 \mathrm{~mm}$ sodium, $75 \mathrm{~mm}$ potassium, and $2 \mathrm{~mm}$ calcium. Thus, accumulation of intracellular calcium appears to be one factor contributing to neuronal damage during ischemia.

Our results suggest that an influx of sodium can also contribute to neuronal damage during conditions of extreme energy deprivation. Elevated intracellular sodium levels may result in the release of calcium from intracellular storage sites (Blaustein and Ector, 1976; Carafoli and Compton, 1978; Siesjö, 1981), thus giving rise to damaging levels of intracellular calcium. Elevated internal $\mathrm{Na}$ ' may also produce damage by osmotic effects, giving rise to severe cell swelling and/or swelling of intracellular organelles.

Postischemic cell survival rates in high-potassium (75 mM) and low-potassium (5 mM), high-choline (112 mM) solutions were similar, indicating that elevated potassium concentrations are not required for cell protection by low-sodium and lowcalcium solutions. Cells exposed to high-potassium (75 mM) solutions in the presence of oxygen (aerobic metabolism) for 5 hr swell and bear some resemblance to postischemic cells. The major difference is that, upon return to normal medium, the swelling is immediately reversed with no permanent damage. Although there have been reports of neuronal survival being increased in culture by elevated potassium levels (Chalazonitis and Fischbach, 1980; Lasher and Zagon, 1972), the levels in question are in the range of $25-40 \mathrm{~mm}$ and refer to growing cells in this medium. In the present experiments, the cells were grown in $5 \mathrm{~mm}$ potassium and exposed to high-potassium solutions only during the ischemic period.

Rothman (1984) found that DGG, an agent that blocks
$N$-methyl-D-aspartate (NMDA) receptors, protects cultured hippocampal cells from anoxia. Another NMDA receptor agonist, 2-amino-7-phosphonoheptanoic acid, was found to protect against ischemic damage in vivo (Simon et al., 1984). It is interesting that DGG was able to protect hippocampal cells from anoxic damage when the extracellular fluid contained physiologic levels of sodium and calcium but was not able to protect our basal ganglia neurons from ischemic damage under similar ionic conditions. DGG was, however, able to prolong the survival of the basal ganglia cells when the extracellular calcium concentration was decreased to $1 \mu \mathrm{M}$. DGG is known to inhibit $90 \%$ of the NMDA-related synaptically evoked response in frog motoneurons at a concentration of only $0.25 \mathrm{~mm}$ (Francis et al., 1980). This suggests that, at the concentrations used in the 2 studies (8-10 mM), DGG may be acting as a sodium flux blocker, perhaps indirectly by blocking synaptic activity, and so reducing depolarization-gated $\mathrm{Na}^{+}$influx. This is consistent with Rothman's observation that TTX, a drug that blocks sodium-dependent action potentials, also protected hippocampal cells from anoxic damage.

Contrary to some theories (for review, see Siesjö, 1981), we have found that neurons can tolerate significant elevations in lactate levels; exposure to $20 \mathrm{~mm}$ lactate for $24 \mathrm{hr}$ resulted in little or no toxicity. Studies on cryoprotective agents have shown that 15-30 mm lactate is actually beneficial to cells stored at 2$8^{\circ} \mathrm{C}$ for $1-3$ weeks (Kawamoto and Barrctt, 1986). These lactate levels are considerably higher than the extracellular concentrations of 12-14 mM commonly observed following ischemia in vivo. The tolerance of cultured neurons to lactate makes it possible to remove all traces of glucose from the medium and yet maintain oxidative metabolism by replacing glucose in the medium with $5 \mathrm{~mm}$ lactic acid; cultured neurons can survive more than $48 \mathrm{hr}$ in this lactate medium. However, our results do not totally eliminate the possibility that lactate accumulation contributes to ischemic damage in vivo. It is possible that the $\mathrm{pH}$ change produced by lactic acid accumulation in vivo, rather than the presence of lactate per se, might be damaging to neurons. In culture systems the large volume and buffering capacity of the medium compared to the low cell volume minimize any cell-derived $\mathrm{pH}$ changes that may occur.

We found that the extent of ischemic damage varied more with the age of the culture than with the tissue source; neuronal cultures from cortex, basal ganglia, and spinal cord were all vulnerable to the combined deprivation of glucose and oxygen for $5 \mathrm{hr}$. Cells in culture less than 2 weeks were particularly insensitive to this deprivation and could withstand periods of up to $8 \mathrm{hr}$ of the ischemia-like conditions. This critical 2 week growth period corresponds to the time of glial and neuronal maturation in culture (Fukatsu et al., 1983; Romijn et al., 1981). Rothman (1983) found a similar age dependence of neuronal vulnerability to anoxic damage and suggested that it might be related to the development of spontaneous electrical activity in culture during this period.

Tissue culture models clearly do not provide precise replicates of all the conditions found in ischemia in vivo, yet they can serve as model systems for studying mechanisms of neuronal damage in isolation from some of the complexities of the in vivo system. The present model utilizes primary cultures of embryonic rat brain neurons, which differ from intact tissue in several major respects. Neurons in culture grow as a monolayer rather than as a mass of cells, such that diffusion may be less limiting for the supply or elimination of substances to or from the cells. The differences in cell density between the culture system and the in vivo situation may affect the levels of spontaneous electrical activity, density, targeting of synaptic innervation, and rates of energy utilization. Our culturing system preferentially selects for an enriched neuronal population with only a $10 \%$ non-neuronal contamination, possibly eliminating many glial influences. De- 
spite these differences, the model does offer a simplified system in which to monitor directly the response of neurons to ischemia-like conditions and to explore means of prolonging their survival.

\section{References}

Ames, A., and F. B. Nesbett (1983a) Pathophysiology of ischemic cell death: I. Time of onset of irreversible damage; Importance of the different components of the ischemic insult. Stroke 14: 219-226.

Ames, A., and F. B. Nesbett (1983b) Pathophysiology of ischemic cell death: II. Changes in plasma membrane permeability and cell volume. Stroke 14: 227-233.

Ames, A., and F. B. Nesbett (1983c) Pathophysiology of ischemic cell death: III. Role of extracellular factors. Stroke 14: 233-240.

Blaustein, M. P., and A. C. Ector (1976) Carrier-mediated sodiumdependent and calcium-dependent calcium efflux from pinched-off presynaptic nerve terminals (synaptosomes) in vitro. Biochim. Biophys. Acta 419: 295-308.

Carafoli, E., and M. Crompton (1978) The regulation of intracellular calcium by mitochondria. Ann. NY Acad. Sci. 307: 269-284.

Chalazonitis, A., and G. D. Fischbach (1980) Elevated potassium induces morphological differentiation of dorsal root ganglionic neurons in dissocialed cell culture. Dev. Biol. 78: 173-183.

Francis, A. A., A. W. Jones, and J. C. Watkins (1980) Dipeptide antagonists of amino acid-induced and synaptic excitation in the frog spinal cord. J. Neurochem. 35: 1458-1460.

Fukatsu, R., M. Pocchiari, T. Aoki, J. Sotelo, C. J. Gibbs, and D. C. Gajdusek (1983) Ultrastructural studies on synaptic formations in dissociated fetal mouse brain cultures. Neurosci. Lett. 43: 127-130.

Kaufman, L. M., and J. N. Barrett (1983) Serum factor supporting long-term survival of rat central neurons in culture. Science 220: 1394-1396.

Kawamoto, J. C., and J. N. Barrett (1986) Cryopreservation of primary neurons for tissue culture. Brain Res. (in press).

Lasher, R. S., and I. S. Zagon (1972) The effect of potassium on neuronal differentiation in cultures of dissociated newborn rat cerebelluril. Brain Res. 41: 482-488.

Phillips, H. J. (1973) Quantitative methods for measuring cell growth and death. In Tissue Culture Methods and Applications, P. F. Kruse, Jr., and M. K. Patterson, Jr., eds., pp. 406-408, Academic, New York.

Romijn, H. J., M. T. Mud, A. M. M. C. Habets, and P. S. Wolters (1981) A quantitative electron microscopic study on synapse formation in dissociated fetal rat cerebral cortex in vitro. Dev. Brain Res. 1: 591-605.

Rothman, S. M. (1983) Synaptic activity mediated death of hypoxic neurons. Science 220:536-537.

Rothman, S. M. (1984) Synaptic release of excitatory amino acid neurotransmitter mediates anoxic neuronal death. J. Neurosci. 4: 18841891.

Rotman, B., and B. W. Papermaster (1966) Prospectus of living mammalian cells as studied by enzymatic hydrolysis of fluorogenic esters. Proc. Natl. Acad. Sci. USA 55: 134-141.

Schanne, F. A. X., A. B. Kane, E. E. Young, and J. L. Farber (1979) Calcium dependence of toxic cell death: A final common pathway. Science 206: 700-702.

Siesjö, B. K. (1981) Cell damage in the brain: A speculative synthesis. J. Cereb. Blood Flow Metab. 1: 155-185.

Simon, R. P., J. H. Swan, T. Griffiths, and B. S. Meldrum (1984) Blockade of $N$-methyl-D-aspartate receptors may protect against ischemic damage in the brain. Science 226: 850-852. 